\title{
Bi-columnar fixation of displaced distal humeral metaphyseal fractures in children: functional outcome assessment of 100 fractures
}

\author{
Mohamad Gouse, Manoharan Muthulingam*, Nandakumar Rangarajan
}

Department of Orthopaedics Mahatma Gandhi Medical College and Research Institute, Puducherry, India

Received: 01 October 2019

Revised: 16 October 2019

Accepted: 17 October 2019

\section{*Correspondence:}

Dr. Manoharan Muthulingam,

E-mail: drmmanoharan@yahoo.com

Copyright: () the author(s), publisher and licensee Medip Academy. This is an open-access article distributed under the terms of the Creative Commons Attribution Non-Commercial License, which permits unrestricted non-commercial use, distribution, and reproduction in any medium, provided the original work is properly cited.

\section{ABSTRACT}

Background: Supracondylar fractures of the humerus are one of the commonest fractures encountered around the elbow in children. The treatment of these fractures continues to pose challenges even in this age of advancing orthopedics. These fractures have the propensity to go for malunion with cosmetic deformity. This study was done to evaluate the functional results of surgical management of supracondylar fractures of the humerus in children using closed reduction and percutaneous bi-columnar pinning technique.

Methods: 100 patients with Gartlands type II, III and IV supracondylar humerus fractures were operated with closed reduction and pinning using K-wires. Patients were followed up at six weeks, twelve weeks and six months and final evaluation were done using the Mayo elbow performance score (MEPS).

Results: In our study, there were 70 males and 30 female patients with mean age of 6.5 years. 85 cases were had fall on outstretched hand as mode of injury and rest following motor vehicle accident. Gartland type II fractures accounted for 10 cases; type III fractures accounts 88 cases and type IV was only 2 cases. Excellent to good results were seen in 80 cases as per the MEPS at 6 months follow-up.

Conclusions: From our study, we could conclude that closed reduction and bi- column percutaneous pinning offers a reliable fixation which permits early mobilization and good functional outcome in displaced fractures. Increasing the number of wire will allow early mobilization and prevent stiffness.

Keywords: Supracondylar fracture, Pediatric fracture, Percutaneous pinning, Bowman's angle, MEPS, Early mobilization

\section{INTRODUCTION}

Distal humeral metaphyseal fractures in children is the most common injury which accounts $60 \%$ of injuries around the elbow and $3 \%$ of all the fractures in the paediatric age group. ${ }^{1-3}$ Supracondylar region is the weakest part in the distal humerus in children because of coranoid fossa anteriorly and olecrenon fossa posteriorly, fracture happens due to fall on extended elbow with hyperextended wrist which will lock the olecrenon in the olecrenon fossa and fractures the humerus just above or through the fossa. ${ }^{4}$ Magnitude force and severity of fracture produces displacement of distal fragment into anterior or posterior and this determines the acute complication. Being a metaphyseal fracture, union is not always a problem; malunion and cosmetic deformity are the most common late complication if not appropriately treated. ${ }^{5}$ Neurovascular injuries are very common with this fracture occurs in 5-10 years of age group. These fractures are classified by Gartland's into three types based on the displacement of distal fragment. ${ }^{5}$ Leitch et al described a new type IV fracture in 2006, in this type complete rupture of periosteum happens at the time of injury or at the time of multiple attempts of reduction, ended up with unstable fracture reduction which cannot be maintained neither in hyper flexion nor in extension. 
Multidirectional unstable type IV fractures can be diagnosed only at intra operatively during the attempt of closed reduction. ${ }^{6}$

These fracture needs anatomical reduction to prevent various complications like neurovascular injury, compartment syndrome, myositis ossificans, deformity and stiffness of elbow joint. Various treatment options like closed reduction and percutaneous pinning (CRPP), closed reduction and long arm plaster of paris, Dunlop's adhesive traction, operative reduction and $\mathrm{K}$ wire fixation, external fixation and skeletal traction are well documented. However, CRPP is time tested gold standard method..$^{7-9}$ Opening of fracture and fixation with $\mathrm{k}$ wire were associated with complication like blood loss, stiffness of joint, infection, scars formation, risk of neurovascular injury. In CRPP like cross K-wire fixation, two parallel lateral column $\mathrm{k}$ wire, divergent lateral $\mathrm{K}$ wire fixation was explained well in the literature. Out of which we have chosen cross K-wire fixation in our study due to its superior stability than any other method in controlling rotational displacement type III fractures. In this type of configuration one can start mobilizing the elbow earlier to avoid elbow stiffness. The objective of this study was to analyze the functional outcome of cross K-wire pinning in paediatric displaced supracondylar humerus fracture.

\section{METHODS}

After institution review board clearance and with informed parental consent, 100 consecutive patients were included in this prospective, interventional study which was conducted at Mahatma Gandhi Medical College and Research Institute, Puducherry between February 2016 to August 2018. All patient's demographic data, mode of injury, presentation to hospital were documented. Gartland's type I fractures, open fractures and associated vessel injury, nerve injury, compartment syndrome, delayed presentation ( $>12$ days), irreducible fracture cases were excluded. All fractures were classified according to modified Gartland's classification. All the patients were done in supine position after combined general anesthesia and regional block. C-arm is used as arm table in most of the cases. Fractures were reduced by Charnley's reduction method, giving longitudinal traction and counter-traction in the upper arm by assistant surgeon to disimpact the fracture fragments, after that mediolateral tilt correction done and finally extension was corrected by maintaining the traction with flexing the elbow and elbow was locked in hyperflexion and full pronation in posteromedial displacement, hyperflexion and full supination in posterolateral displacement. Reduction is confirmed with image intensifier by taking jones views and lateral view by externally rotating the arm. Achievement of reduction is confirmed with bowman's angle in anteroposterior view, anterior humeral line in lateral view, getting both supracondylar ridges in line. Lateral wire done first with 120 degree flexion $1.8 \mathrm{~mm} \mathrm{k}$ wire passed from lateral condyle and directed 35 to 45 degree angle in anterior posterior view and 10 degree in lateral view, wire is driven intramedullary to get far cortex purchase. The second medial wire performed in 90 degrees' flexion with parallel orientation to the lateral $\mathrm{K}$-wire after protecting the ulnar nerve. Third K-wire inserted from lateral side for reinforcing the stability. All the cases $\mathrm{K}$ wires were crossed minimum of $1 \mathrm{~cm}$ above the olecranon fossa. Stability of elbow is checked by taking the elbow in full range of motion (Figure 1a-1c).
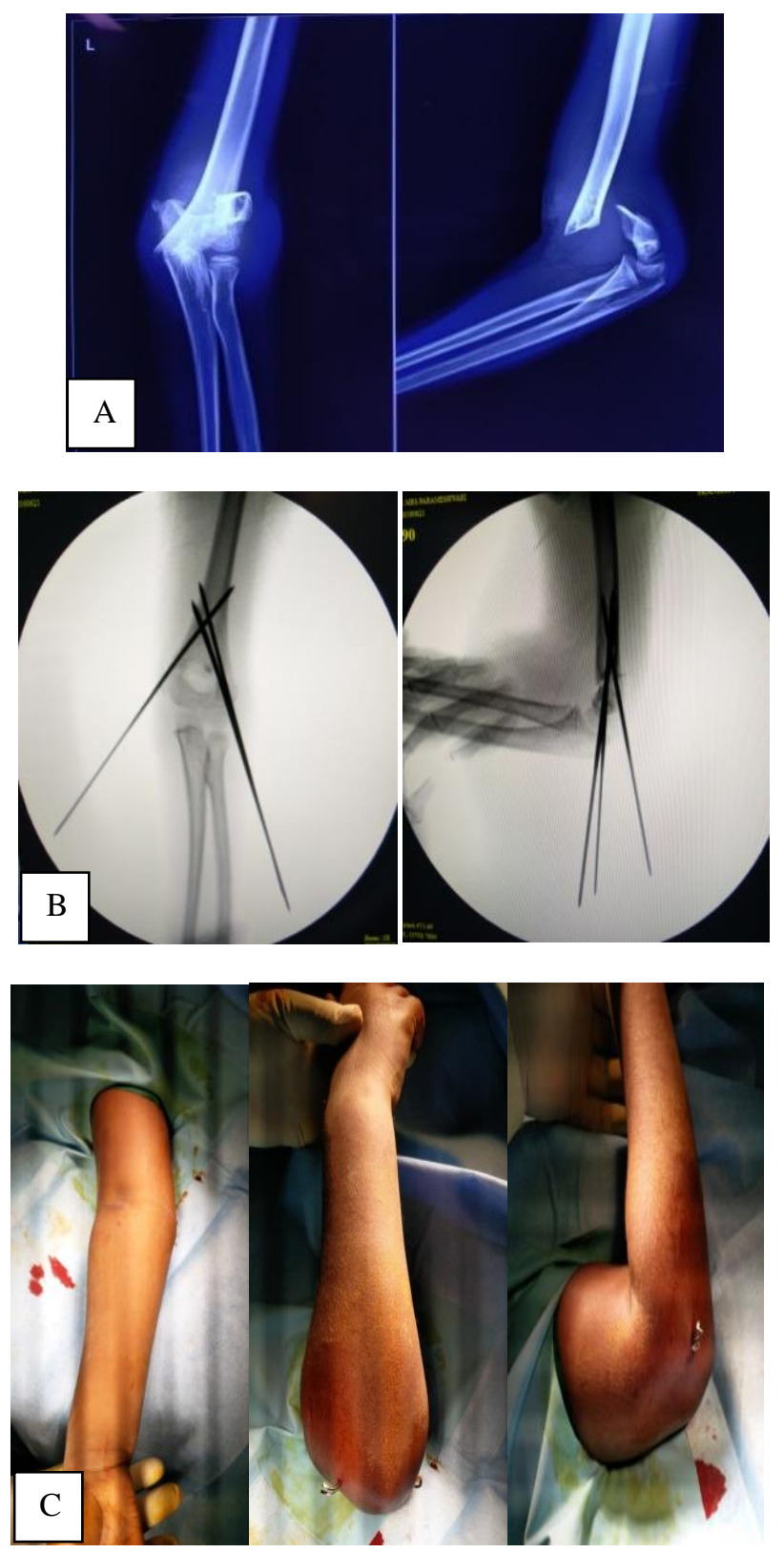

Figure 1 (A): Anteroposterior and lateral view of $\mathrm{X}$-ray of 6-year-old girl; (B): Intra operative fleuroscopic pictures and (C): Intra op clinical pictures.

$\mathrm{K}$-wires are bent, cut and left outside to facilitate the later removal easy. Distal pulses were checked throughout the procedure. Above elbow point of pressure splint was 
applied in all patients for 2 week to facilitate soft tissue healing. All the patients were discharged after 48 hours. All patients were reviewed 2 weeks, 1 and 11/2 month. Removal of K-wires at 4-6 weeks depending upon the radiological signs of progression on union. Each follow up fracture healing is assessed clinically and radiologically. Data entry and analysis were done by using Epi Info software. Elbow function is assessed using Mayo's elbow performance score (MEPS) and based on the scores excellent, good, fair and poor results were categorized. MEPS was assessed during 6, 12 weeks and 6 months to assess the functional outcome of the patients.

\section{RESULTS}

In our study we have complete follow up of 6 months for all cases. $68 \%$ of cases had non-dominant side fracture (Table 1 and 2).

Table 1: Sex incidence.

\begin{tabular}{|l|l|l|}
\hline & Male & Female \\
\hline Right side & 22 & 10 \\
\hline Left side & 48 & 20 \\
\hline
\end{tabular}

Table 2: Age incidence.

\begin{tabular}{|lll|}
\hline Age distribution (in years) & No. of cases & $\%$ \\
\hline$<\mathbf{5}$ & 10 & 10 \\
\hline $\mathbf{5 - 1 0}$ & 76 & 76 \\
\hline$>\mathbf{1 0}$ & 14 & 14 \\
\hline
\end{tabular}

Table 3: Classification of fractures.

\begin{tabular}{|lll|}
\hline $\begin{array}{l}\text { Modified Gartland } \\
\text { classification }\end{array}$ & No. of cases & $\%$ \\
\hline Type II & 10 & 10 \\
\hline Type III A & 62 & 62 \\
\hline Type III B & 26 & 26 \\
\hline Type IV & 2 & 2 \\
\hline
\end{tabular}

Table 4: Mayo elbow performance score (MEPS).

\begin{tabular}{|llll|}
\hline Score & $\mathbf{6}$ weeks & $\mathbf{1 2}$ weeks & $\mathbf{6}$ months \\
\hline Excellent & 70 & 76 & 76 \\
\hline Good & 10 & 4 & 4 \\
\hline Fair & 20 & 20 & 20 \\
\hline Poor & 0 & 0 & 0 \\
\hline
\end{tabular}
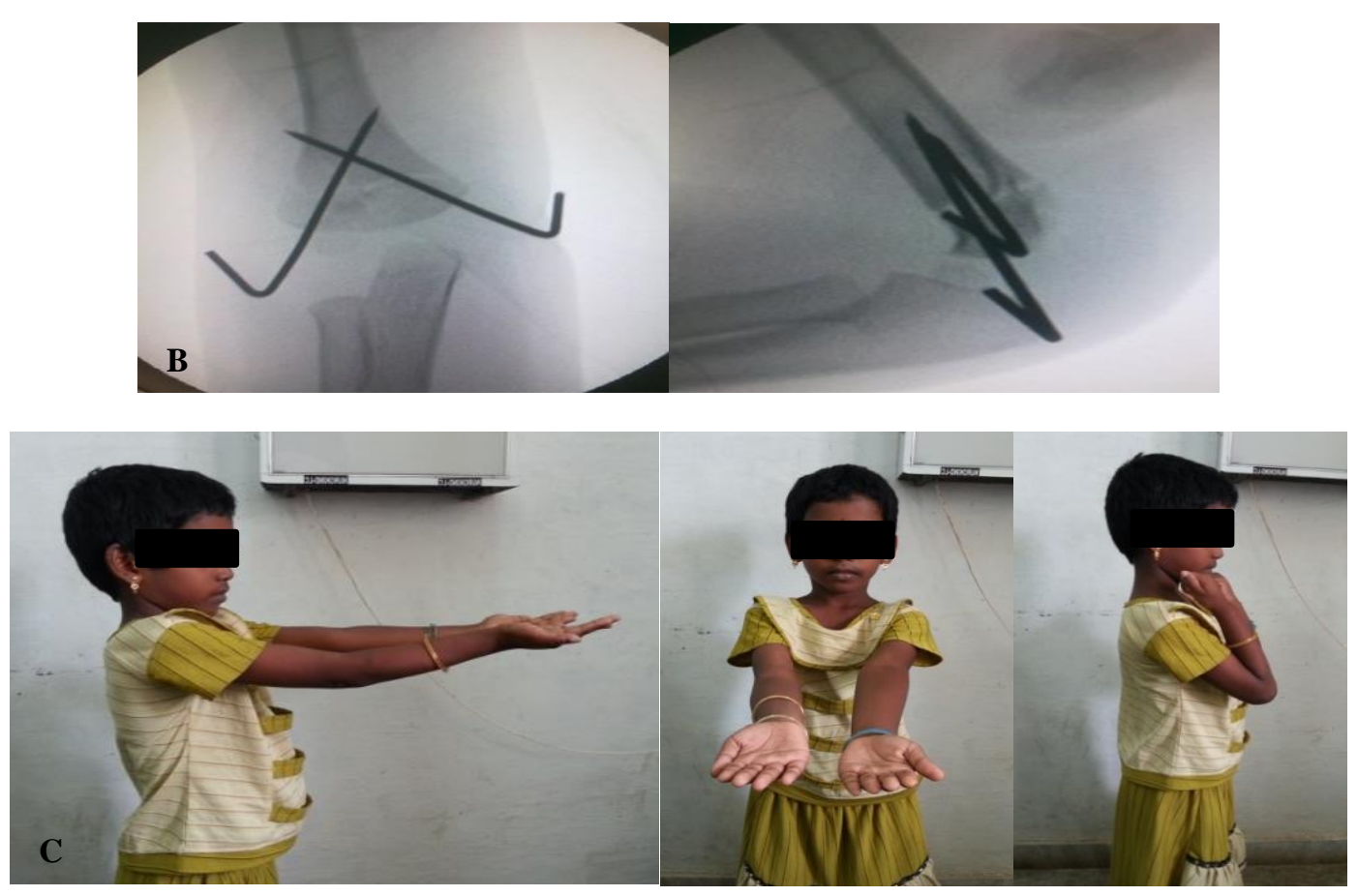

Figure 2 (A): Pre-operative X-ray; (B): post-operative X-ray showing accurate anatomical reduction and (C): clinical picture at the end of six months. 
$85 \%$ of case had injury due to fall on outstretched hand. In this $62 \%$ of cases had posteromedial displacement and $26 \%$ of cases presented with posterolateral displacement. Eight patients presented with feeble pulse in initial presentation. According to modified Gartland's classification $88 \%$ cases fall in type III fractures (Table 3 ). All these patients had restoration of pulse after close reduction and K-wire fixation. 54 cases were got operated within first 24 hours of injury (54\%), $46 \%$ cases operated after 48 hours of injury. In these 25 cases, 2 (8\%) cases presented after native bandage application with gross swelling, these patients were initially treated with limb elevation and followed by fixation (Figures 2a-2c). Eight patient had pin tract infection which settled after removal. Ulnar nerve neuro-praxia found in 6 cases pre operatively which was recovered without any intervention. Three patients had loss of reduction where fracture configuration was oblique in sagittal plane. None of the cases were developed cubitus varus or valgus deformity at final follow up at the end of 2 years. As per MEPS 76 were excellent, 4 were good, 20 were fair and no case was categorized as poor (Table 4).

\section{DISCUSSION}

Successful outcome of treatment of the displaced supracondylar in children are based on achieving and maintaining good reduction. The mean age and sex incidence observed in our study was comparable to the studies of Green et al. ${ }^{10}$ Ziouts et al concluded that bicolumn fixation provides greater torsional rigidity than lateral entry pin fixation. Divergent nature of these two $\mathrm{K}$-wire above the fracture site improves the total strength of the construct. Bi-column fixation is considered as more stable biomechanical construct, however, it adds to the risk of ulnar nerve injury especially when elbow is grossly swollen, as palpation of ulnar nerve becomes difficult. ${ }^{11,12}$ Similar results were observed in Swenson et al using crossed pin fixation. ${ }^{13}$ The greatest strength of divergent pins was related to the location of the intersection of the two pins and the fact that the amount of divergence between the two pins allow greater purchase in the medial and lateral column. There are few studies authors who advocated the use of the third wire to prevent rotational displacement of the distal fragment. ${ }^{13}$ Karim et al, done a prospective randomized control trial on comparison of crossed vs lateral pin fixation in type II and type III fractures and concluded that crossed pin fixation was superior in terms of achieving stability at fracture site and found statistically significant difference in stability. Fracture pattern, surgeons experience, divergence of wire fixation will influence the functional outcome. ${ }^{14}$ Distal humeral metaphyseal fractures always has a chance for iatrogenic ulnar nerve palsy with the use of medial pin and the percentage of ulnar nerve injuries varies in between the studies. In the present study the ulnar nerve palsy was found preoperatively $6 \%$ which recovered spontaneously without any interventions. Lyons et al have encountered in $6 \%$ of cases, Royce et al, reported as $3 \%, 58 \%$ cases of nerve injury noted by
Agus in his study. ${ }^{15,16}$ Most of the time postoperative nerve palsies were direct injury to the nerve, not due to manipulation of the fracture. Reynolds et al concluded that percutaneous crossed pinning of displaced supracondylar fractures of humerus in children is a simple, safe and effective method even with delayed presentation. ${ }^{17}$

\section{CONCLUSION}

Achievement of anatomical reduction is the goal of the treatment of displaced paediatric supracondylar humerus fractures. This reduction was maintained by a fixation with a good stability and minimal complications. Considering all the principles in the management of fractures, we conclude that closed reduction and percutaneous crossed pinning is a gold standard, effective, affordable reproducible and safe method. Advantage of early mobilization will prevent elbow stiffness which is possible by additional $\mathrm{K}$-wire fixation.

\section{Funding: No funding sources Conflict of interest: None declared \\ Ethical approval: The study was approved by the Institutional Ethics Committee}

\section{REFERENCES}

1. Battaglia TC, Armstrong DG, Schwend RM. Factors affecting forearm compartment pressures in children with supracondylar fractures of the humerus. J Pediatr Orthop. 2002;22:431-9.

2. Lee SS, Mahar AT, Miesen D. Displaced pediatric supracondylar humerus fractures, biomechanical analysis of percutaneous pinning techniques. J Pediatr Orthop. 2002;22:440-3.

3. Mapes R, Hennrikus W. The effect of elbow position on the radial pulse measured by Doppler ultrasonography after surgical treatment of supracondylar elbow fractures in children. J Pediatr Orthop. 1998;18:441-4.

4. Cheng JC, lam TP, Maffulli N. Epidemiological features of supracondylar fractures of the humerus in Chinese children. J Pediatr Orthop B. 2001;10(1):63-7.

5. Rasool MN. Ulnar nerve injury after K-wire fixation of supracondylar humerus fractures in children. $\mathbf{J}$ Pediatr Orthop. 1998;18:686-90.

6. Leitch KK, Kay RM, Femino JD. Treatment of multidirectionally unstable supracondylar humeral fractures in children. A modified Gartland type-IV fracture. J Bone Joint Surg [Am]. 2006;88-A (5):980-5.

7. Skaggs DL, Cluck MW, Mostofi A. Lateral-entry pin fixation in the management of supracondylar fractures in children. $\mathbf{J}$ Bone Joint Surg. 2004;86A:702-7.

8. Gartland J. Management of Supracondylar Fractures in Children. Surg Gynecol Obstet.1959;109:145. 
9. Mazda K, Boggione C, Fitoussi F, Pennecot GF. Systematic pinning of displaced extension type of supracondylar fractures of the humerus in childrena prospective study of 116 consecutive patients. J Bone Joint Surg [Br]. 2001;83:888-93.

10. Green DW, Widmann RF, Frank JS, Gardner MJ. Low incidence of ulnar nerve injury with crossed pin placement for paediatric Supracondylar humerus fractures using a mini-open technique. J Orthop Trauma. 2005;19:158-63.

11. Zionts LE, Mckellop HA, Hathaway R. Torsional strength of pin configurations used to $\mathrm{X}$ supracondylar fractures of the humerus in children. $\mathrm{J}$ Bone Joint Surg Am. 1994;76:253-6.

12. Onwuanyi ON, Nwobi DG. Evaluation of the stability of pin configuration in K-wire fixation of displaced supracondylar fractures in children. Int Surg. 1998;83:271-4.

13. Swenson AL. Treatment of supracondylar fractures of the humerus by Kirschner wire trans xion. J Bone Joint Surg Am. 1948;30:993-7.

14. Karim MA, Hosny A, Nasef Abdelatif NM, Hegazy MM, Awadallah WR. Crossed wires versus two lateral wires in management of supracondylar fracture of the humerus in children in the hands of junior trainees. J Orthop Trauma. 2016;30(4):123-8.

15. Royce RO, Dutkowsky JP, Kasser JR, Rand FR. Neurologic complications after K-wire fixation of Supracondylar humerus fractures in children. J Pediatr Orthop. 1991;11:191-4.

16. Agus H, Kelenderer O, Kayali C. Closed reduction and percutaneous pinning results in children with Supracondylar humerus fractures. Acta Orthop Traumatol Turc. 1999;33:18-22.

17. Reynolds RA, Mirzayan R. A technique to determine proper pin placement of crossed pins in supracondylar fractures of the elbow. J Pediatr Orthop. 2000;20:485-9.

Cite this article as: Gouse M, Muthulingam M, Rangarajan N. Bi-columnar fixation of displaced distal humeral metaphyseal fractures in children: functional outcome assessment of 100 fractures. Int J Res Orthop 2019;5:1202-6. 